\title{
Collaboration for community-based wildlife management
}

\author{
Daniel J. Decker · Daniela B. Raik • Len H. Carpenter • \\ John F. Organ · Tania M. Schusler
}

(C) Springer Science + Business Media, LLC 2006

Erratum to: Urban Ecosyst

DOI: $10.1007 / \mathrm{s} 11252-005-3264-6$

The online author listing in the HTML version unfortunately contained typographical errors. The correct author listing is: Daniel J. Decker · Daniela B. Raik · Len H. Carpenter · John F. Organ - Tania M. Schusler. The author list appeared correctly in the printed version and in the PDF file.

The online version of the original article can be found at http://dx.doi.org/10.1007/s11252-005-3264-6

Daniel J. Decker $(\bowtie)$

Human Dimensions Research Unit, 245 Roberts Hall, Cornell University, Ithaca, NY 14853

e-mail: djd6@cornell.edu

Daniela B. Raik

Human Dimensions Research Unit, 306 Fernow Hall, Cornell University, Ithaca, NY 14853

e-mail: dbr23@cornell.edu

Len H. Carpenter

Wildlife Management Institute, 4015 Cheney Drive, Fort Collins, Colorado 80526

e-mail: lenc@verinet.com

John F. Organ

Wildlife Program Chief, Division of Federal Aid, 300 Westgate Center Drive, Hadley, MA 01035

e-mail: John_Organ@fws.gov

Tania M. Schusler

Environmental Issues Educator, Cornell Cooperative Extension of Tompkins County, 615 Willow Avenue, Ithaca, NY 14850

e-mail: tms23@cornell.edu 